\title{
DETERMINAÇÃO DA QUALIDADE FÍSICO-QUÍMICA E MICROBIOLÓGICA DO QUEIJO MINAS FRESCAL ARTESANAL COMERCIALIZADO EM UMA CIDADE DA ZONA DA MATA MINEIRA
}

Bianca Clemente Motta, Letícia Monteiro Farias. Determinação da qualidade do queijo minas frescal artesanal comercializado em uma cidade da zona da Mata Mineira. Revista Saúde Dinâmica, vol. 3, núm.1, 2020. Faculdade Dinâmica do Vale do Piranga. 


\title{
Determinação da qualidade físico-química e microbiológica do queijo minas frescal artesanal comercializado em uma cidade da Zona da Mata mineira
}

\section{Determination of physicochemical and microbiological quality of cheses mines artesanal freshes marked in a city of mineira zone}

\author{
Bianca Clemente Motta ${ }^{1 *}$, Letícia Monteiro Farias ${ }^{l}$ \\ ${ }^{1}$ Faculdade Dinâmica do Vale do Piranga. Rua $G, n^{\circ}$ 205. Bairro Paraíso. Ponte Nova- MG. \\ *biancacm20@outlook.com.
}

\section{Resumo}

O queijo Minas frescal é de fabricação simples, baixo custo, alto rendimento e comercializado a preços acessíveis, sendo um dos produtos lácteos mais vendidos em feiras, bares, supermercados. Esse alimento quando produzido artesanalmente, podem apresentar desvios em sua qualidade, devido a não padronização da fabricação e/ou não cumprimento das boas práticas de fabricação. $\mathrm{O}$ presente trabalho avaliou as características físico-químicas e microbiológicas de queijos Minas frescal produzidos artesanalmente por oito produtores rurais de uma cidade da Zona da Mata Mineira. Das amostras avaliadas neste estudo foi observado pelos resultados físicoquímicos variações consideráveis nos parâmetros de $\mathrm{pH}$, acidez e teor de $\mathrm{NaCl}$ entre as amostras analisadas e entre os resultados em triplicata da mesma amostra, demonstrando possíveis problemas durante a homogeneização da massa. Já sobre os resultados microbiológicos obtidos no presente trabalho, foi possível concluir que todos os queijos analisados apresentavam grandes quantidades UFC/g de todos os microrganismos, podendo assim estar em desacordo com a legislação vigente. Considerando o fato que o queijo Minas frescal é amplamente consumido pela população, este estudo demonstrou que há necessidade de maior atenção e de cuidados com as questões de padronização e de higiene durante a fabricação do queijo Minas frescal, visando garantir sua qualidade e segurança aos consumidores.

Palavras-chave: Queijo Minas frescal artesanal; Qualidade; Análises físico-químicas; Análises microbiológicas.

\begin{abstract}
Minas frescal cheese is simple to manufacture, low cost, high yield and marketed at affordable prices, being one of the most sold dairy products at fairs, bars, supermarkets. This food, when produced by hand, may present deviations in its quality, due to non-standard manufacturing and / or non-compliance with good manufacturing practices. The present work evaluated the physical-chemical and microbiological characteristics of Minas frescal cheeses produced by hand by eight rural producers in a city in Zona da Mata Mineira. From the samples evaluated in this study, considerable variations in the parameters of $\mathrm{pH}$, acidity and $\mathrm{NaCl}$ content were observed by the physicochemical results between the analyzed samples and between the triplicate results of the same sample, showing possible problems during the homogenization of the mass. Regarding the microbiological results obtained in the present study, it was possible to conclude that all the cheeses analyzed presented large amounts CFU / $g$ of all microorganisms, thus being in disagreement with the current legislation. Considering the fact that Minas frescal cheese is widely consumed by the population, this study demonstrated that there is a need for greater attention and care with issues of standardization and hygiene during the manufacture of Minas frescal cheese, in order to guarantee its quality and safety to consumers.
\end{abstract}

Keywords: Minas frescal cheese; Quality; Physicochemical analysis; Microbiological analyzes. 


\section{INTRODUÇÃO}

De origem brasileira, o queijo Minas frescal é considerado um dos queijos mais populares do país, sendo consumido por todas as camadas sociais (SANGALETTI, 2007). Sua produção é uma prática que representa tradição familiar que corta gerações, sendo fonte ou complemento orçamentário para muitas famílias. Esse tipo de queijo geralmente é fabricado por produtores rurais, que destinam parte do leite ordenhado para a produção do alimento, seja para consumo próprio ou com o objetivo de comercializá-lo. Por se tratar de um produto artesanal, muitas vezes, seu processo de fabricação é realizado sem cuidados com as questões de higiene e boas práticas de fabricação, chegando a ser produzido até mesmo dentro de currais, aumentando, de forma significativa, as chances de contaminação (SILVA; LEITÃO, 1980).

O queijo Minas frescal é um queijo semi-gordo, de muito alta umidade. É obtido pela coagulação enzimática do leite com coalho, podendo ou não conter outras enzimas coagulantes apropriadas, complementada ou não com ação de bactérias lácticas especificas (BRASIL, 1997). Apresenta consistência macia, textura que pode apresentar ou não olhaduras mecânicas ("buracos" na massa do queijo, formado durante a fabricação), cor esbranquiçada, sabor suave ou levemente ácido, odor suave e característico (BRASIL, 2004).

Segundo a última pesquisa realizada pela Associação Brasileira das Indústrias de Queijo (ABIQ), em 2011, o país produziu 867 mil toneladas do produto, tendo um aumento de 9,4\% com relação a 2010 (SEBRAE, 2014). A produção nacional de queijo concentra-se, principalmente, em Minas Gerais, que em 2012 foi responsável pela fabricação de mais de 200 mil toneladas do produto, sendo 70 mil de queijo Minas artesanal (SILVA; TUNES; CUNHA, 2012).

O queijo Minas frescal é de fabricação simples, baixo custo, alto rendimento e comercializado a preços acessíveis, sendo um dos produtos lácteos mais vendidos em feiras, bares, supermercados. Geralmente são envasados em sacos plásticos fechados com nó ou fechos metálicos (HOFFMAN; et al., 2002). Esse tipo de alimento pode ter sua origem industrial, fabricado por laticínios, os quais são inspecionados e fiscalizados segundo a legislação vigente, e também de forma artesanal que são produzidos de maneira informal sem qualquer inspeção (RODRIGUES, 2013). 
Os queijos artesanais apresentam variações em suas características e, como são fabricados em locais diversos, por diferentes processos, muitas vezes sem qualquer padronização, podem apresentar desvios na qualidade, não oferecendo nenhuma garantia de segurança alimentar (SILVA; TUNES; CUNHA, 2012).

A boa procedência do leite é primordial para a obtenção de um produto de boa qualidade. Apesar das exigências legais, para que o leite destinado à fabricação de queijos passe por processos de higienização e sejam submetidos à pasteurização, é intensa a comercialização de produtos que não cumprem essas especificações. Somado a isso, a contaminação do leite póspasteurização, o uso de fermentos impróprios, temperaturas e condições de manufatura e armazenagem incorretas contribuem ainda mais para a má qualidade do produto final (MACEDO, 2008).

Acredita-se que muitos queijos Minas frescal comercializados no Brasil não estão aptos para o consumo humano devido ao fato de não estarem de acordo com a legislação vigente. É comum a presença de depósito de soro na embalagem do queijo Minas frescal, e isso está relacionado à sua elevada umidade e por não ser prensado durante sua fabricação. A dessora do queijo contribui de forma significativa para o crescimento microbiano e ainda deixa o alimento com um aspecto menos atrativo (PINTO; et al.; 2011).

Por apresentar elevada umidade e ser altamente perecível, o queijo Minas frescal apresenta características propícias para contaminação, sobrevivência e multiplicação de bactérias, que podem ser patogênicas ou produzir toxinas causando intoxicações e infecções alimentares nos seres humanos (SALOTTI, et al., 2006). Essas condições se agravam quando processados com leite cru, sem o emprego das boas práticas de fabricação e tecnologia adequada, ou ainda, sem se observar o tempo mínimo de maturação (OLIVEIRA; SILVA; CARVALHO, 2018).

Considerando a falta de padronização, os diferentes fatores que podem levar à contaminação do queijo Minas frescal e o elevado consumo desse tipo de queijo no país, tornase de suma importância verificar a qualidade desse alimento. Portanto, este trabalho teve como objetivo avaliar a qualidade dos queijos Minas artesanais fabricados por produtores rurais em uma cidade da Zona da Mata mineira, por meio da análise de suas propriedades físico-químicas, tais como: potencial hidrogeniônico $(\mathrm{pH})$, acidez, umidade e teor de cloreto de sódio $(\mathrm{NaCl})$, bem como das propriedades microbiológicas incluindo contagem de coliformes totais, 
Staphylococcus spp. e mesófilos totais. Posteriormente, tais resultados foram comparados as especificações definidas pela legislação nacional vigente.

\section{MATERIAIS E MÉTODOS}

Foram analisadas quinze amostras de queijo Minas frescal fabricados artesanalmente por oito produtores rurais de uma cidade da Zona da Mata Mineira. As amostras foram obtidas de supermercados ou diretamente das residências dos produtores, entre os meses de abril e julho de 2019. As mesmas foram adquiridas na véspera das análises, armazenadas em bolsas térmicas com gelo e transportadas para o laboratório Multidisciplinar II da Faculdade Dinâmica para a execução dos ensaios físico-químicos e para um laboratório colaborador para a realização dos ensaios microbiológicos. Todos os exemplares foram mantidos sob refrigeração $\left(4 \pm 1^{\circ} \mathrm{C}\right)$ até o momento das análises.

As oito primeiras amostras foram destinadas para a execução das análises físico-químicas e, posteriormente, mais sete amostras dos mesmos produtores foram designadas para as análises microbiológicas. Para o ensaio microbiológico, não foi possível a obtenção de oito amostras, devido ao fato de um dos produtores ter cessado a fabricação de queijo.

As amostras foram identificadas como A1, A2, A3, A4, A5, A6, A7 e A8, de acordo com a ordem de aquisição.

\section{Análises físico-químicas}

As análises físico-químicas foram realizadas conforme a metodologia da Association of Official Agricultural Chemists (1995) descrita em Dias; et al. (2016). Todas as análises foram realizadas em triplicata, a temperatura das amostras durante as análises variou entre 4 a $6^{\circ} \mathrm{C}$, exceto a durante a análise da unidade, que as amostras foram submetidas a elevadas temperaturas.

Inicialmente, foram pesados em balança analítica (Shimadzu ${ }^{\circledR}$ AX200) cerca de 5 gramas (g) de cada amostra (retiradas em partes diferentes do queijo) em béquer de 150 mililitros (mL). Em seguida, foram adicionados aproximadamente $50 \mathrm{~mL}$ de uma solução (1:1) de água destilada e soro do próprio queijo. Posteriormente, todo o conteúdo foi macerado para 
dissolução das amostras. Após o preparo das amostras, as mesmas foram submetidas aos ensaios imediatamente.

\section{Determinação do pH e Acidez Titulável}

Para a determinação do pH foi utilizado pHmetro (Hanna® pH 21 pH/mV meter) previamente calibrado. $\mathrm{O}$ eletrodo e o sensor de temperatura foram introduzidos diretamente nos béqueres contendo as amostras, e em seguida, os valores foram anotados. Ao final de cada análise, o eletrodo foi lavado com água destilada e seco com papel de textura macia para evitar contaminação cruzada.

A acidez titulável foi definida por meio de titulação de neutralização da amostra com solução volumétrica de Hidróxido de Sódio a 0,1 mol litro-1 ( $\mathrm{NaOH} \mathrm{0,1} \mathrm{mol} \mathrm{L-1)} \mathrm{previamente}$ padronizada, em presença do indicador fenolftaleína. Os resultados foram expressos em porcentagem de ácido lático, calculados a partir de 5,0 g da amostra (DIAS; et al. 2016).

\section{Determinação da Umidade}

A umidade foi determinada pelo método de secagem em estufa até peso constante. Em vidro de relógio previamente dessecado em estufa (Brasdonto®) por uma hora a temperatura de $105^{\circ} \mathrm{C}$, pesou-se cerca de $5 \mathrm{~g}$ de cada amostra em triplicata. As amostras foram colocadas em estufa a uma temperatura de $100^{\circ} \mathrm{C}$ e, após duas horas, foi realizada a primeira pesagem. A segunda pesagem foi realizada após 3 horas e, a terceira, após 5 horas em estufa. Após cada pesagem, as amostras foram resfriadas em recipiente de vidro com tampa, contendo sílica. A temperatura variou entre 100 a $105^{\circ} \mathrm{C}$, e a pesagem da amostra foi realizada após o arrefecimento da mesma (DIAS; et al. 2016).

\section{Determinação do Teor de Cloreto de Sódio ( $\mathrm{NaCl})$}

Para a determinação do teor de $\mathrm{NaCl}$ utilizou-se cerca de 5,0 g das amostras dissolvidas em 50 mL de uma solução (1:1) de água destilada e soro do próprio queijo. As titulações foram realizadas com solução volumétrica de Nitrato de Prata a 0,1 mol L-1 (AgNO3 0,1 mol L-1) previamente padronizada em presença do indicador Cromato de Potássio (DIAS; et al. 2016). 


\section{Análises Microbiológicas}

O experimento foi conduzido segundo metodologia descrita por Freitas (2015), com algumas adaptações. Todas as análises foram realizadas utilizando-se material estéril e capela de fluxo laminar (Grupo VECO® BIO SEG 12). Realizou-se também o controle negativo de todos os meios utilizados.

\section{Preparo das amostras e diluições}

Para as análises microbiológicas foi realizada a desinfecção das embalagens das amostras com álcool 70\% sendo as mesmas abertas com tesoura. Com o auxílio de uma espátula foram pesadas cerca de $25,0 \mathrm{~g}$ de cada amostra, transferidas para recipientes contendo $225 \mathrm{~mL}$ de água peptonada $0,1 \%$. Em seguida, as amostras foram homogeneizadas por aproximadamente dois minutos, considerando a diluição 10-1.

A partir dessa diluição inicial, foram preparadas uma série de diluições decimais 10-2 e 10-3, utilizando-se 9,0 mL de água peptonada $0,1 \%$ e $1,0 \mathrm{~mL}$ da diluição anterior, perfazendo um volume final de 10,0 mL. As diluições foram empregadas para a realização de todo o ensaio microbiológico.

\section{Coliformes Totais}

Para a contagem de coliformes totais, foi inoculado $1,0 \mathrm{~mL}$ de cada diluição sobre a superfície de placas contendo ágar MacConkey (Neogen®), sendo o inócuo espalhado com o auxílio da alça de Drigalski. As placas invertidas de cada amostra foram incubadas entre $35^{\circ} \mathrm{C}$ a $37^{\circ} \mathrm{C}$, por 48 horas, em estufa microbiológica (Quimis ${ }^{\circledR}$ Q316M2).

\section{Staphylococcus spp.}

Para pesquisa de Staphylococcus spp., foi semeado 1,0 mL de cada diluição sobre a superfície de placas contendo ágar Sal Manitol (Kasvi®). O inoculo foi espalhado com o auxílio de uma alça de Drigalsky e as placas invertidas de cada amostra foram incubadas entre $35^{\circ} \mathrm{C} \mathrm{a}$ $37^{\circ} \mathrm{C}$, por 48 horas, em estufa bacteriológica (Quimis® Q316M2).

\section{Mesófilos Totais}

Para contagem de mesófilos totais, foi inoculado $1,0 \mathrm{~mL}$ de cada diluição utilizando a técnica de profundidade, em que o ágar Soja Tripticaseina (Neogen®) foi despejado sobre 
placas estéreis contendo as diluições de cada amostra. As placas invertidas de cada amostra foram incubadas entre $35^{\circ} \mathrm{C}$ a $37^{\circ} \mathrm{C}$, por 48 horas, em estufa bacteriológica (Quimis ${ }^{\circ}$ Q316M2).

\section{RESULTADOS E DISCUSSÃO}

Todas as amostras adquiridas encontravam-se sob refrigeração $\left(4 \pm 1^{\circ} \mathrm{C}\right)$ no momento da compra, embaladas em saco plástico e fechadas com nós.

Nas embalagens das amostras não havia nenhuma informação referente à data de fabricação, validade, número do lote e composição nutricional.

\section{Análises Físico-Químicas}

\section{1 pH e Acidez Titulável}

Segundo Amiot; Scott (1991), não é definido por legislação os parâmetros de acidez e pH para queijo Minas frescal artesanal, mesmo esses sendo fatores de grande importância para determinar e avaliar a qualidade dos queijos, uma vez que indicam o estado de degradação do produto. Em cartilha da Embrapa, que dispõe sobre a produção do queijo Minas artesanal, é citado que o produto acabado apresente $\mathrm{pH}$ entre 5,0 e 5,3 (SILVA, 2005). 
Tabela 1- Resultado das análises físico-químicas ( $\mathrm{pH}$, acidez, umidade, teor de $\mathrm{NaCl}$ ) das amostras.

\begin{tabular}{ccccccccc}
\hline & \multicolumn{7}{c}{$\mathbf{p H}$} \\
\hline Amostra & $\mathbf{A 1}$ & $\mathbf{A 2}$ & $\mathbf{A 3}$ & $\mathbf{A 4}$ & $\mathbf{A 5}$ & $\mathbf{A 6}$ & $\mathbf{A 7}$ & $\mathbf{A 8}$ \\
Média & 6,29 & 5,10 & 6,49 & 5,98 & 5,62 & 6,50 & 5,45 & 6,52 \\
DP* & 0,13 & 0,01 & 0,09 & 0,09 & 0,01 & 0,03 & 0,01 & 0,03 \\
\hline \multicolumn{7}{c}{ Acidez $^{1}$} \\
\hline Média & 1,43 & 5,49 & 0,26 & 1,11 & 1,17 & 0,25 & 0,56 & 0,57 \\
DP* & 0,24 & 0,81 & 0,09 & 0,19 & 0,008 & 0,03 & 0,04 & 0,02 \\
\hline \hline \multicolumn{7}{c}{ Umidade $^{2}$} \\
\hline Média & 55,42 & 58,88 & 56,46 & 57,92 & 60,67 & 53,68 & 48,70 & 62,67 \\
DP* & 32,01 & 1,71 & 0,19 & 2,24 & 1,11 & 2,97 & 1,37 & 0,34 \\
\hline \multicolumn{7}{c}{ Teor de NaCl } \\
\hline Média & 3,19 & 2,12 & 4,84 & 7,21 & 2,36 & 3,60 & 1,62 & 2,33 \\
DP* & 1,94 & 0,16 & 0,12 & 1,77 & 0,24 & 0,15 & 0,10 & 1,17 \\
\hline
\end{tabular}

Fonte: Elaborado pela autora.

${ }^{1}$ Valores de acidez expressos em \% (g de ácido lático/g de queijo). ${ }^{2}$ Valores de umidade expressos em (\%). ${ }^{3}$ Valores de Teor de $\mathrm{NaCl}$ expressos em $\mathrm{g} / \mathrm{mL}$ de cloreto de sódio. * Desvio Padrão.

$\mathrm{O}$ valor do $\mathrm{pH}$ das amostras analisadas (Tabela1) variou entre 5,10 e 6,52, podendo observar a proximidade dos valores das três medições de cada amostra, indicando precisão nos resultados encontrados. Essa variação encontrada pode estar relacionada devido ao tempo e temperatura de armazenamento dos produtos. Estudos realizados por Ricardo; et al. (2011) mostraram que os valores do $\mathrm{pH}$ de 10 amostras de queijo Minas analisadas variaram entre 5,20 e 6,78. O pH das amostras analisadas não apresenta valores dentro do que é descrito em cartilha da Embrapa disponibilizada para produtores rurais.

Dias; et al. (2016), encontraram resultados semelhantes de $\mathrm{pH}$ das amostras analisadas com variação entre 5,4 e 6,7. Valores de pH entre 5,36 e 6,54 foram encontrados por Landim (2001) no estudo físico-químico e bioquímico de queijos Minas frescal vendidos no sudoeste da Bahia. $\mathrm{O}$ pH mede a concentração de hidrogênios dissociados no queijo, o que permite avaliar as modificações biológicas, químicas e bioquímicas no produto (SCOTT, 1991; FURTADO, 1999).

A partir da acidez titulável é possível determinar a quantidade de ácido lático presente em produtos lácteos, além de avaliar, de forma indireta, a concentração de proteínas, ácidos graxos, e outros compostos como fosfatos, citratos, carbonatos e sulfatos de cálcio e magnésio 
(AMIOT; SCOTT; 1991). Os valores da triplicata da acidez titulável dos queijos expressa em porcentagem (\%) das amostras A2, A3 e A4 apresentaram maior variação dos resultados, quando comparadas a outras amostras.

No estudo realizado por Ricardo; et al. (2011), os queijos artesanais analisados apresentaram a média da acidez entre 0,06 e 2,41\%. A Tabela 1 exibe que, segundo as médias encontradas neste trabalho, a acidez variou entre 0,25 e 5,49\%.

Um fator que interfere na acidez dos queijos é a condição de armazenamento, pois dependendo das condições da temperatura que estão expostos, os queijos podem sofrer alterações tornando-se mais ácidos (DIAS; et al., 2016). A amostra A2 apresentou maior teor de acidez e menor valor de $\mathrm{pH}$, podendo assim, apresentar um sabor mais ácido.

Pesquisas já realizada mostraram uma grande variação nos valores de acidez dos queijos artesanais. $\mathrm{O}$ teor de ácido láctico pode sofrer influências da ação de microrganismos presentes no leite, das variações dos processos de fabricação e utilização do "pingo", que age como um fermento natural. Entretanto, a acidez excessiva pode prejudicar as características sensoriais dos queijos por produzir acentuado sabor ácido descaracterizando o produto (SILVA; TUNES; CUNHA, 2012).

O aumento da acidez em \% de ácido lático é inversamente proporcional à redução do pH. O aumento da acidez geralmente está diretamente relacionado com o aumento do número de microrganismos psicrotróficos mesófilos e principalmente bactérias láticas, que são os agentes protagonizantes da transformação da lactose em ácido lático (SANGALETTI, 2007).

\subsection{Umidade}

A classificação dos queijos quanto ao teor de umidade descrito na Portaria $\mathrm{N}^{\circ} .146$ do Ministério da Agricultura, Pecuária e Abastecimento (MAPA), de 07 de março de 1996, se divide em quatro tipos: queijos de baixa umidade: umidade até 35,9\%; queijos de média umidade: umidade entre 36,0\% e 45,9\%; queijos de alta umidade: umidade entre 46,0 e 54,9\% e queijos de muito alta umidade: umidade não inferior a 55,0\% (BRASIL, 1996).

De acordo com a Instrução Normativa n ${ }^{\circ} 4$ de 2004 do MAPA, o queijo Minas frescal é caracterizado como queijo de muito alta umidade, e conforme a legislação, queijos com essa classificação devem possuir umidade não inferior a 55,0\% (BRASIL, 2004). 
Conforme Tabela 1, pode-se observar que as amostras A6 e A7 não se encontraram na classificação do queijo Minas frescal quanto à umidade, apresentando valores inferiores ao critério estabelecido na legislação.

Segundo estudo realizado por Silva (2008), as amostras de queijo Minas frescal fabricados por agricultores familiares na região de Guarapuava, apresentaram variação dos valores de umidade entre 36,40 e $61,67 \%$, demonstrando a falta de padrão na elaboração desse tipo de queijo na região. Ricardo; et al. (2011) obteve resultados semelhantes em seu estudo, no qual 50\% das amostras analisadas não apresentaram umidade dentro da classificação do queijo Minas frescal, sendo que duas amostras enquadravam-se como queijos de alta umidade e, uma amostra, apresentava teor de umidade de queijos classificados como queijo de baixa umidade.

Neste estudo, os valores de umidade variaram entre 48,7 e 62,37\%, e das amostras analisadas, 25\% estavam em desacordo em relação à umidade. Esses resultados diferem dos obtidos por Dias et al. (2016), em que todas as amostras apresentaram valores de umidade variando entre 56 e $63,7 \%$.

\subsection{Teor de $\mathrm{NaCl}$}

Conforme valores do teor de $\mathrm{NaCl}$ dispostos na Tabela 1, pode-se observar que a distribuição do sal durante o processo de salga na fabricação do queijo não ocorre de maneira uniforme, apresentando assim partes do queijo com maior quantidade de sal do que outras. As amostras A1, A4 e A8 apresentaram maiores discrepância dos valores em triplicata no teor de $\mathrm{NaCl}$ em relação as outras amostras analisadas.

$\mathrm{O}$ teor diversificado de $\mathrm{NaCl}$ nos queijos Minas artesanais está relacionado às variações de quantidade e metodologia adotada pelo produtor durante o processo de salga do queijo. Regularmente, a quantidade de $\mathrm{NaCl}$ utilizada varia de acordo com a preferência e conhecimentos adquiridos pelos produtores rurais com a arte de fabricar queijos (SILVA; TUNES; CUNHA 2012).

Grandes variações no teor de $\mathrm{NaCl}$ tornam-se preocupantes pelo fato de que, os queijos fabricados sem maiores conhecimentos tecnológicos podem apresentar concentrações variadas de sal, desde quantidades pequenas até níveis muito elevados, levando a uma despadronização do produto (ARRUDA; et al., 2010). 
Em Dias; et al. (2016), os teores de $\mathrm{NaCl}$ das amostras analisadas apresentaram variação entre $0,7 \%$ e 1,4\%. Já Aguiar; Torres; Souza (2013) encontraram uma variação entre 2 e 2,5\% de $\mathrm{NaCl}$ cloreto de sódio. No presente trabalho, resultados superiores foram encontrados e a média dos teores de $\mathrm{NaCl}$ nas amostras analisadas variaram entre 1,62 e 7,21\%, conforme demonstra a tabela 4 .

Queijos Minas frescal artesanais fabricados nas regiões do Serro, Canastra e Cerrado do Estado de Minas Gerais foram analisados por Oliveira; et al., (2013) e apresentaram os seguintes resultados em relação ao teor de $\mathrm{NaCl}$ 1,77\% (Serro), 1,86\% (Canastra) e 2,62\% (Cerrado). Em comparação aos resultados obtidos, provavelmente os queijos em estudo apresentam sabor mais salgado quando comparados aos queijos produzidos nessas três regiões de Minas Gerais. Nobrega et al. (2006), em seu estudo feito com queijos Minas frescal artesanais, obteve resultados dos valores de $\mathrm{NaCl}$ com variação entre 4 e $11 \%$.

$\mathrm{O}$ teor de $\mathrm{NaCl}$ constitui um dos aspectos que influencia na qualidade do queijo por desempenhar diversas funções, dentre elas a proteção contra microrganismos indesejáveis, complementação da dessoragem, melhora do sabor, redução da umidade e da atividade de água do produto, regulação da maturação e solubilização das proteínas, melhorando a textura do queijo (DIAS; et al., 2016).

\subsection{Análises Microbiológicas}

Os resultados referentes às análises microbiológicas encontram-se dispostos na Tabela 2, expressos como Unidade Formadora de Colônias por grama (UFC)/g e Unidade Formadora de Colônias Estimado por grama (UFCEST)/g.

Tabela 2- Resultado da pesquisa de Staphylococcus aureus, Coliformes Totais e Mesófilos Totais expressos em UFC/g e UFCEST/g.

\begin{tabular}{cccc} 
Amostra & Mesófilos Totais & Staphylococcus spp. & Coliformes Totais \\
\hline A1 & - & - & -
\end{tabular}




\begin{tabular}{lccc} 
A2 & $2,49 \times 10^{4 *}$ & $1,53 \times 10^{4 *}$ & Incontável \\
A3 & $2,43 \times 10^{4 *}$ & Incontável & $4,4 \times 10^{3 *}$ \\
A4 & $2,08 \times 10^{4 *}$ & $1,42 \times 10^{4 *}$ & $6,1 \times 10^{4^{*}}$ \\
A5 & Incontável & $2,15 \times 10^{5 * *}$ & $3,24 \times 10^{4 * *}$ \\
A6 & $2,28 \times 10^{4 *}$ & $3,76 \times 10^{5 * *}$ & Incontável \\
A7 & $2,36 \times 10^{4 *}$ & $2,49 \times 10^{4 *}$ & Incontável \\
A8 & $3,08 \times 10^{5 * *}$ & $1,63 \times 10^{4 *}$ & $5,6 \times 10^{3 *}$ \\
\hline
\end{tabular}

Fonte: Elaborado pela autora.

*UFC/g **UFCEST/g.

Não se pôde confirmar o tipo de microrganismo que se desenvolveu nas amostras analisadas, por não ter sido realizado os testes confirmatórios, e nem realizar a pesquisa de microrganismos exigidos pela legislação utilizando metodologias padronizadas por falta de recursos estruturais e financeiros. As análises microbiológicas então foram realizadas apenas por meio da contagem das colônias típicas dos microrganismos em estudo, nos meios de cultura utilizados.

Os padrões microbiológicos para queijos estabelecidos no Brasil apresentam variações de acordo com o tipo de queijo. A Resolução da Diretoria Colegiada n ${ }^{\circ} 12$ de 2001 da Agência Nacional de Vigilância Sanitária (ANVISA) estabelece como parâmetros microbiológicos para queijo Minas frescal a ausência de Salmonella spp. e de Listeria monocytogenes em 25g do alimento, além dos limites máximos de $5 \times 10^{2} \mathrm{UFC}^{-1} \mathrm{~g}^{-1}$ ou Número Mais Provável por grama $\left(\right.$ NMP. $\left.\mathrm{g}^{-1}\right)$ para coliformes termotolerantes e para bactérias do grupo dos estafilococos coagulase positiva (BRASIL, 2001).

Dos meios de cultura utilizados, o ágar MacConkey é empregado para o isolamento e diferenciação de bacilos entéricos Gram-negativos. Microrganismos fermentadores de lactose como Escherichia coli, crescem como colônias rosa, podendo ou não ter a presença de uma zona de precipitado de bile. Dos resultados obtidos com a inoculação das amostras no ágar MacConkey, pode-se observar o crescimento de colônias de coloração rosa (Figura 1), semelhantes às colônias de Escherichia coli, sendo assim indicativo a presença desse microrganismo em todas as amostras. 
Figura 1- Resultado da incubação das placas de petri com as diluições $10^{-1}, 10^{-2}$ e $10^{-3}$ da amostra A3, semeadas no ágar MacConkey.

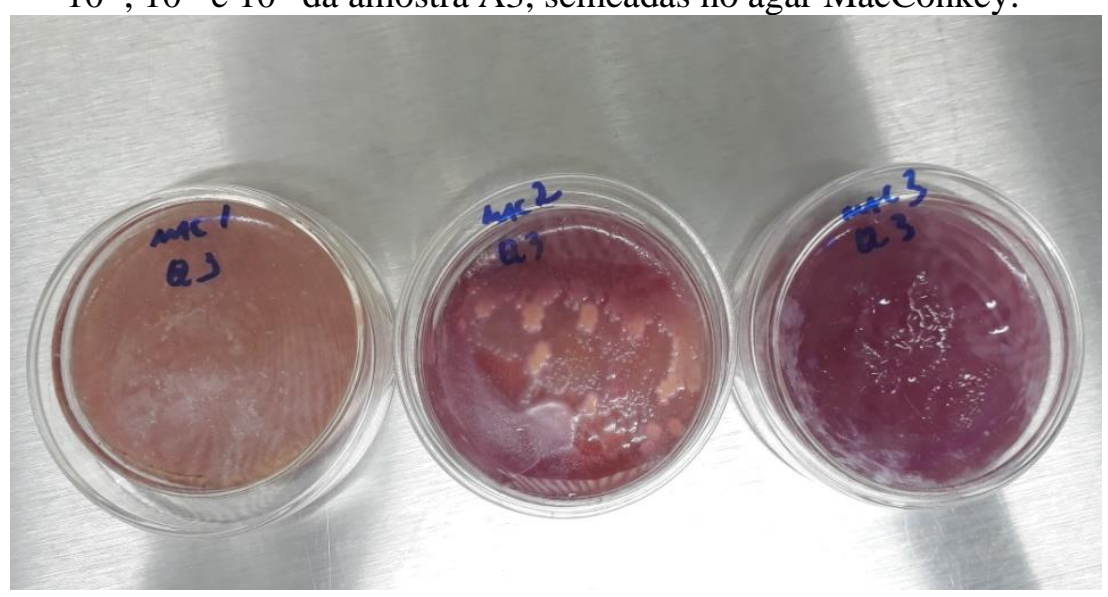

Fonte: Elaborado pela autora.

O ágar Sal Manitol é utilizado para isolamento e enumeração de Staphylococcus patogênicos. Nesse meio de cultura, houve o crescimento de colônias amarelas típicas de Staphylococcus aureus, em todas as placas. Na diluição $10^{-3}$ de todas as amostras houve o crescimento de colônias pequenas, rodeadas por uma zona vermelha, indicativo de Staphyloccus não patogênicos. Também houve o crescimento de colônias brancas típicas de Staphylococcus epidermidise, conforme demonstrado na Figura 2.

Figura 2- Resultado da incubação das placas de petri com as diluições

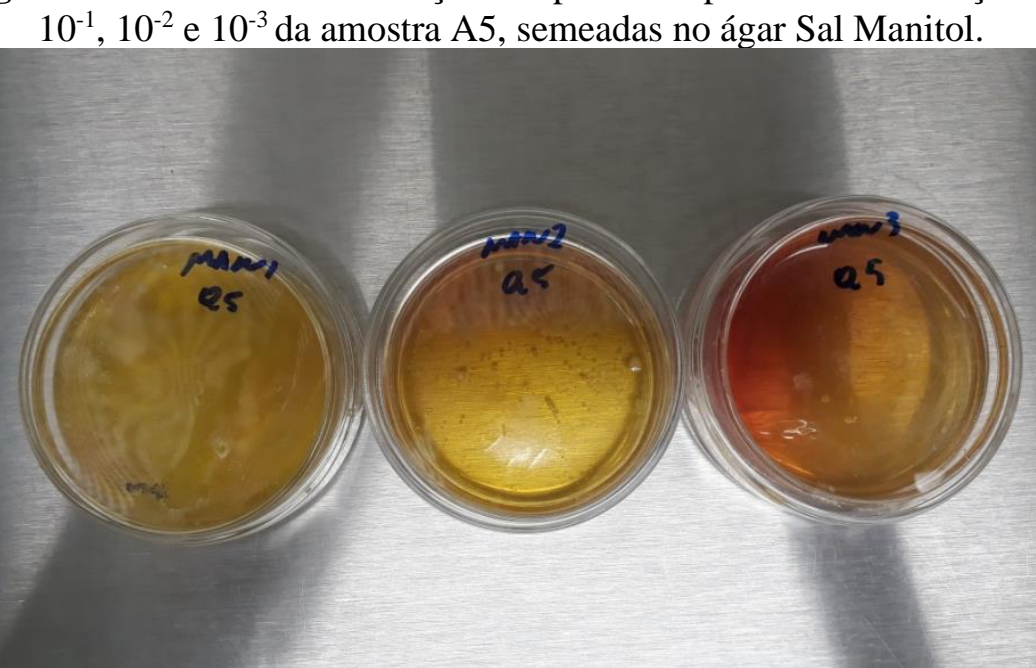

Fonte: Elaborado pela autora.

O ágar Soja Tripticaseina é utilizado para o cultivo de ampla variedade de microrganismos. Dos resultados obtidos através da inoculação das amostras no referido meio 
de cultura, foi possível observar o crescimento de colônias brancas e amarelas de diversos tamanhos (Figura 3).

Figura 3- Resultado da incubação das placas de petri com as diluições $10^{-1}$, $10^{-2}$ e $10^{-3}$ da amostra A5, semeadas no ágar Soja Tripticaseina.

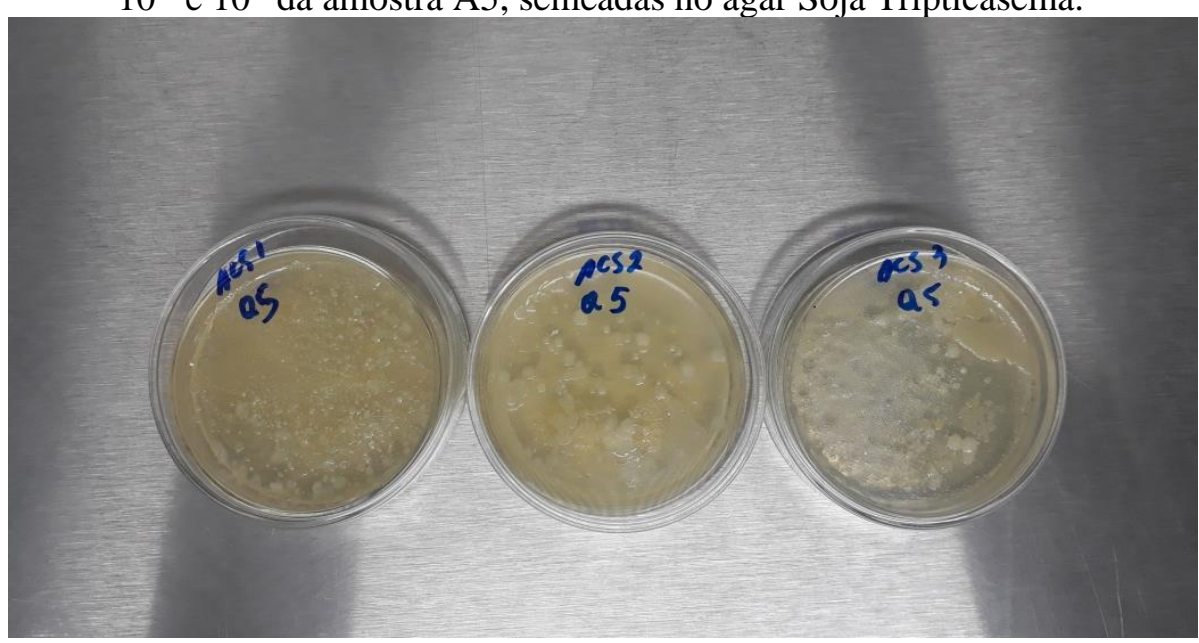

Fonte: Elaborado pela autora.

Todas as amostras em estudo apresentaram resultados de UFC's extremamente elevados, sugerindo contagem dos microrganismos acima do permitido pela legislação vigente, indicando insatisfatória a qualidade higiênico-sanitária dos queijos, oferecendo risco potencial à saúde do consumidor. Para tal confirmação, é necessária a pesquisa de Salmonella spp. e de Listeria monocytogenes, juntamente com a contagem de coliformes termotolerantes e de bactérias do grupo dos estafilococos coagulase positiva.

O não cumprimento das boas práticas de fabricação e más condições de armazenamento favorecem consideravelmente a contaminação do queijo, podendo assim ter contribuído para a elevada quantidade de UFC/g dos microrganismos pesquisados nas amostras.

Além disso, fatores específicos que caracterizam o queijo Minas frescal favorecem o desenvolvimento de microrganismos. Parâmetros como alta atividade de água, umidade acima de 55\% e a não maturação estão relacionadas com a elevada carga microbiana e menor vida útil desse tipo de queijo (BELOTI; et al., 2015).

Dias; et al. (2016), avaliando a qualidade microbiológica e físico-química de queijo Minas frescal artesanal e industrializado, observaram, contagem microbiológica acima da padronizada pela legislação vigente, sugerindo ausência de controle em pontos essenciais como higiene durante a fabricação, observação quanto a temperaturas adequadas de armazenamento 
e/ou utilização de matérias-primas de qualidade higiênico-sanitária. Resultado semelhante foi apontado no estudo de Salotti; et al. (2013) no qual 66,7\% das amostras de queijo Minas artesanal analisadas encontravam-se em desacordo com as exigências legais.

Passos; et al. (2009), ao analisar 15 amostras de queijo Minas frescal artesanal, constatou que 14 amostras estavam fora dos limites para Staphylococcus aureus, 9 com contagens acima do permitido para E. Coli e 15 amostras com contagens superiores a $10^{3} \mathrm{UFC} / \mathrm{g}$ para o grupo de coliformes a $35^{\circ} \mathrm{C}$.

Coliformes, quando presentes em limites superiores ao que é exigido pela legislação, é indicativo de má qualidade microbiológica do produto em função da falta de higiene durante a fabricação, tornando o queijo impróprio para o consumo devido ao risco da presença de microrganismos patogênicos (OLIVEIRA; et al., 2017).

Oliveira; et al. (2017), em estudo sobre a qualidade dos queijos Minas frescal comercializados no norte do Pará, observaram que 55,6\% das amostras encontravam-se em desacordo com o determinado para coliformes totais. Já Apolinário; et al. (2014), segundo a análise de queijos Minas artesanais em Minas Gerais, na região da Zona da Mata, mostraram que $77,4 \%$ das amostras analisadas encontravam-se com valores de coliformes totais acima do definido pela legislação.

No presente trabalho, $42,85 \%$ das amostras analisadas apresentaram quantidades de UFC/g incontáveis para coliformes totais e 57,14\% apresentaram contagens elevadas para esses microrganismos, o que torna evidente o grau de contaminação das amostras por bactérias patológicas e a falta de assepsia no preparo dos alimentos.

Macedo (2008) detectou contagem de coliformes totais e termotolerantes acima dos limites especificados pela legislação, em todas as cinco amostras de queijo Minas frescal estudadas. Resultado semelhante foi observado neste estudo em que a contagem para coliformes de todas as amostras encontravam-se em quantidades elevadas, podendo assim estar fora da faixa permitida pela legislação.

Os coliformes totais comumente são contaminantes ambientais, e por mais que sua contagem não seja exigida pela legislação vigente para produtos comercializados, faz-se importante a análise desse microrganismo, pois contagem elevada de coliformes totais indica deficiência na qualidade higiênico-sanitária do produto (BRANT; et al., 2007).

A presença de Staphylococcus aureus em elevadas contagens nos alimentos, causa uma grande preocupação em relação à capacidade desse microrganismo em produzir enterotoxinas, 
podendo causar uma intoxicação alimentar ao consumidor (FERREIRA et al., 2010). Uma das causas da contagem acima dos valores aceitáveis desse microrganismo pode estar relacionada com a grande manipulação dos queijos, pois os manipuladores representam as principais fontes de transmissão dessa bactéria (Borges; et al., 2008).

Em todas as cinco amostras analisadas no estudo de Macedo (2008), a contagem de Staphylococcus Aureus apresentou-se em desacordo com a legislação vigente. Indicando relação da contaminação com a grande manipulação dos queijos. Esse dado, reforçado pela contagem de coliformes também em desacordo, com os parâmetros legais, sugere que os produtos são impróprios para consumo.

No estudo de Senger; Bizani (2011), das 30 amostras queijo Minas artesanal analisadas, $40 \%$ encontravam-se fora dos padrões estabelecidos pela legislação vigente para contagem de Staphylococcus aureus. Em Loguercio; Aleixo (2001), analisando queijos Minas frescal artesanais em Cuiabá, concluíram que 97\% das amostras apresentavam contagens de Staphylococcus aureus em desacordo com o estabelecido pela legislação.

Para a contagem de colônias típicas de Staphylococcus aureus, apenas a amostra A3 exibiu placas caracterizadas como incontáveis. No entanto, todas as demais amostras analisadas apresentaram contagem elevada para esse microrganismo, expondo valores que variaram entre $3,76 \times 10^{5} \mathrm{UFCEST} / \mathrm{g}$ e $1,42 \times 10^{4} \mathrm{UFC} / \mathrm{g}$.

Em Komatsu; et al. (2010), o resultado da contagem Staphylococcus coagulase positiva apontaram que $88 \%$ das amostras analisadas de queijo Minas frescal produzido em UberlândiaMG apresentavam níveis inaceitáveis para comercialização. Esse resultado foi um pouco inferior aos deste estudo, em que todas as amostras apresentaram níveis muito acima do permitido pela legislação.

A legislação brasileira não define limites para a contagem de microrganismos mesófilos em queijos, porém, contagens na ordem de $10^{5}-10^{6} \mathrm{UFC} / \mathrm{g}$ no alimento sugerem contaminação da matéria prima e/ou condições de fabricação inadequadas (FRANCO; ALMEIDA, 1992).

A contagem de mesófilos totais em amostras de queijo Minas frescal artesanal no estudo de Rodrigues (2013) foi de 5,64 x $10^{5}$ UFC/g. Já no presente estudo, a contagem desse microrganismo variou entre $2,08 \times 10^{4}$ e $3,08 \times 10^{5} \mathrm{UFCEST} / \mathrm{g}$.

As altas cargas microbianas presente nos queijos podem ser sugestivas de problemas como contaminação proveniente dos manipuladores, tratamento térmico ineficiente, má qualidade da matéria-prima ou uso do leite cru, além de contato do alimento com superfícies 
não sanitizadas e temperaturas impróprias para a conservação do produto (PASSOS; et al., 2009).

\section{CONCLUSÃO}

A partir dos resultados físico-químicos das amostras estudadas neste trabalho, pode-se concluir que as boas práticas de fabricação não foram seguidas durante o preparo desses alimentos, não existindo assim uma padronização no processo de fabricação do queijo Minas frescal, pois houve variações consideráveis nos parâmetros de $\mathrm{pH}$, acidez e teor de $\mathrm{NaCl}$ entre as amostras analisadas e entre os resultados em triplicata da mesma amostra. Essas variações podem estar relacionadas a homogeneização não uniforme da massa durante a produção e também devido às particularidades das técnicas de produção empregadas, oriundas da tradição e da cultura de cada produtor.

Já sobre os resultados microbiológicos obtidos no presente trabalho, foi possível concluir que todos os queijos analisados apresentavam grandes quantidades UFC/g de todos os microrganismos, podendo assim estar em desacordo com a legislação vigente, evidenciando possíveis falhas em relação aos procedimentos higiênicos durante a fabricação e/ou uso de matéria-prima de baixa qualidade higiênico-sanitária, tornando assim impróprios para o consumo humano.

Este estudo demonstrou que há necessidade de maior atenção e de cuidados com as questões de padronização e de higiene durante a fabricação do queijo Minas frescal, visando garantir sua qualidade, para que o produto atenda a legislação e normas de fabricação vigente. Considerando o fato que o queijo Minas frescal é amplamente consumido pela população, é de grande importância que haja garantia de qualidade e segurança para os consumidores.

\section{REFERÊNCIAS}

AGUIAR, V. C; TORRES, B. T; SOUSA, C. D. Aspectos físico-químicos, bioquímicos e microbiológicos da maturação de queijos de coalho produzidos com leite bovino. Revista Brasileira de Pesquisa em Alimentos, Campo Mourão-PR, v. 3, n. 2, p. 99-102, 2013. 
Disponível em:

$<$ https://www.researchgate.net/publication/26391885_Queijos_aspectos_quimicos_bioquimic os_e_microbiologicos>. Acesso em: 04 de maio de 2019.

AMIOT, J. Ciencia y tecnologia de la leche. Zaragoza: Acribia, 1991.

APOLINÁRIO, T. C. C.; et al. Avaliação da qualidade microbiológica do queijo Minas Frescal produzido por laticínios do estado de Minas Gerais. Revista do Instituto de Laticínios Cândido Tostes, v. 69, n. 6, p. 433-442, 2014. Disponível em: < https://doi.org/10.14295/2238-6416.v69i6.290 >. Acesso em: 23 de julho de 2019.

ARRUDA, M. L. T.; et al. Determinação de cloreto de sódio, nitrato e nitrito em queijos Minas frescal e padrão comercializados em feiras livres de Goiânia - GO. PUBVET, Londrina, v. 4, n. 18, ed. 123, 2010. Disponível em: < http://www.pubvet.com.br/uploads/0e708a90c15c9b3b0a55ee78189f5f90.pdf>. Acesso em: 04 de maio de 2018.

BELOTI, V.; et al. Enumeração de microrganismos psicrotróficos e termodúricos psicrotroficos de leite: comparação de metodologias. Revista do Instituto de Laticínios Cândido Tostes, v. 70, n. 1, p. 1723, 2015. Disponível em: < https://doi.org/10.14295/22386416.v70i1.360 >. Acesso em: 27 de maio de 2019.

BORGES, M. F.; et al. Staphylococcus enterotoxigênicos em leite e produtos lácteos, suas enterotoxinas e genes associados: revisão. Boletim do Centro de Pesquisa de

Processamento de Alimentos, v. 26, n. 1, p. 70-86, 2008. Disponível em: < http://bases.bireme.br/cgi-

bin/wxislind.exe/iah/online/?IsisScript=iah/iah.xis\&src=google \&base=LILACS\&lang=p\&nex tAction=lnk\&exprSearch=525699\&indexSearch=ID >. Acesso em: 15 de maio de 2019.

BRANT, L. M. F.; FONSECA, L. M.; SILVA, M. C. C. Avaliação da qualidade microbiológica do queijo-de-minas artesanal do Serro- MG. Arquivo Brasileiro de Medicina Veterinária e Zootecnia, v.59, n.6, p.1570-1574, 2007. Disponível em: < http://docplayer.com.br/25455055-Avaliacao-da-qualidade-microbiologica-do-queijo-deminas-artesanal-do-serro-mg.html >. Acesso em: 15 de maio de 2019.

BRASIL. Ministério da Agricultura, Pecuária e Abastecimento. Instrução Normativa No 4, de 01 de março de 2004. Regulamento Técnico para Fixação de Identidade e Qualidade do Queijo Minas Frescal. Diário Oficial da União, Brasília, 05 de março de 2004.

BRASIL. Ministério da Agricultura, Pecuária e Abastecimento. Portaria nº 146 de 7 de março de 1996. Aprova os Regulamentos Técnicos de Identidade e Qualidade dos Produtos Lácteos. Diário Oficial da União 11 mar. 1996; Seção 1.

BRASIL. Ministério da Agricultura, Pecuária e Abastecimento. Portaria no 352 de 4 de setembro de 1997. Aprova o Regulamento Técnico de Identidade e Qualidade de Queijo Minas Frescal. Diário Oficial da União 08 set. 1997; Seção 1. 
DIAS, B. F.; et al. Qualidade microbiológica e físico-química de queijo minas frescal artesanal e industrial. Revista de Agricultura Neotropical, Cassilândia-MS, v. 3, n. 3, p. 5764, jul./set. 2016. Disponível em: <

https://periodicosonline.uems.br/index.php/agrineo/article/view/1211 >. Acesso em: 10 de julho de 2019.

FERREIRA, G. B. et al. Pesquisa de Staphylococcus aureus em queijos tipo "Minas frescal" comercializados na região do Triângulo Mineiro. Revista Baiana de Saúde Pública, v. 34, n. 3, p. 575-589, 2010. Disponível em: < http://files.bvs.br/upload/S/01000233/2010/v34n3/a2066.pdf >. Acesso em: 21 de julho de 2019.

FRANCO, R. M; ALMEIDA, L. E. F. Avaliação microbiológica de queijo ralado, tipo parmesão, comercialização em Niterói, RJ. Revista Higiene Alimentar, v.6, n.21, p.33-36, 1992. Disponível em: < http://bases.bireme.br/cgibin/wxislind.exe/iah/online/?IsisScript=iah/iah.xis\&src=google\&base=LILACS\&lang=p\&nex tAction=lnk\&exprSearch=113427\&indexSearch=ID >. Acesso em: 21 de julho de 2019.

FREITAS, M. P. Avaliação microbiológica de queijos artesanais produzidos na cidade de Taió, Santa Catarina. Saúde Meio Ambient. v. 4, n. 2, p. 103-114, jul./dez. 2015. Disponível em: < http://www.periodicos.unc.br/index.php/sma/article/view/869 >. Acesso em: 23 de julho de 2019.

FURTADO, M. M. Problemas típicos do queijo minas frescal. Principais problemas dos queijos: causas e prevenção. São Paulo-SP: Fonte de comunicações, 1999. p. 155-160.

HOFFMANN, F. L.; SILVA, J. V.; VINTURIM, T. M. Qualidade microbiológica de queijos tipo "Minas Frescal", vendidos em feiras livres na região de São José do Rio Preto, SP.

Higiene Alimentar, São Paulo, v. 16, n. 96, p.69-76, maio, 2002. Disponível em: < http://bases.bireme.br/cgi-

bin/wxislind.exe/iah/online/?IsisScript=iah/iah.xis\&src=google\&base $=$ LILACS\&lang=p\&nex tAction=lnk\&exprSearch=319641\&indexSearch=ID >. Acesso em: 21 de maio de 2019.

KOMATSU, R. S.; et al. Ocorrência de Staphylococcus coagulase positiva em queijos Minas frescal produzidos em Uberlândia-MG. Biosci. J., Uberlândia, v. 26, n. 2, p. 316-321, Mar./Apr. 2010. Disponível em: <

http://www.seer.ufu.br/index.php/biosciencejournal/article/view/7159/4701 >. Acesso em: 04 de julho de 2019.

LANDIM, L. B. Caracterização físico-química e bioquímica de queijos Minas Frescal comercializados na região sudoeste da Bahia. Revista Analytica, n. 5, 2001. Disponível em: $<$ https://periodicos.utfpr.edu.br $>$ rebrapa $>$ article $>$ download $>$. Acesso em 15 de maio de 2019.

LOGUERCIO, A. P.; ALEIXO, J. A. G. Microbiologia de queijo tipo minas frescal produzido artesanalmente. Ciência Rural, Santa Maria, v.31, n.6, p.1063-1067, 2001. Disponível em: <http://www.scielo.br/pdf/cr/v31n6/a24v31n6.pdf >. Acesso em: 23 de julho de 2019. 
MACEDO, D. C. Avaliação microbiológica do queijo Minas frescal comercializado na feira de São Luís de Montes Belos. 2008. 25 f. Artigo. (Tecnólogo em Laticínios) Universidade Estadual de Goiás, São Luís de Montes Belos, 2008. Disponível em: <http://www.cdn.ueg.br/source/campus_sao_luis_de_montes_belos_243/noticias/29226/2008/ Douglas_Candido_de_Macedo.pdf>. Acesso em 23 de abril de 2018.

NOBREGA, J.E.; et al. Perfil do fermento endógeno utilizado na produção do queijo Minas artesanal na Serra da Canastra, Minas Gerais. Anais do XXIII Congresso Nacional de Laticínios, n. 351, vol.61, p.427-429, 2006. Disponível em: < http://locus.ufv.br/handle/123456789/2823 > . Acesso em: 27 de maio de 2019.

OLIVEIRA, D. F.; et al. Caracterização físico-química de queijos minas artesanal produzidos em diferentes microrregiões de Minas Gerais. Revista Brasileira de Economia Doméstica, Viçosa, v. 24, n.2, p. 185-196, 2013.

OLIVEIRA, S. C. P. L; SILVA, A. C.; CARVALHO, M. G. X. Diagnóstico das condições higienicossanitárias do processo de fabricação de queijo de coalho no sertão paraibano.

Higiene Alimentar - Vol.32 - n 284/285 - Set./Out. de 2018. Disponível em: < http://docs.bvsalud.org/biblioref/2018/11/964919/284-285-set-out-2018-66-71.pdf >. Acesso em: 29 de julho de 2019.

OLIVEIRA, A. M.; et al. Condições higiênico-sanitárias da produção de queijos tipo mussarela e Minas frescal comercializados no norte do Paraná. Revista do Instituto de Laticínios Cândido Tostes, Juiz de Fora, v. 72, n. 1, p. 40-47, jan/mar, 2017. Disponível em: < https://www.revistadoilct.com.br/rilct/article/view/556/425 >. Acesso em: 21 de junho de 2019.

PASSOS, A. D.; et al. Avaliação microbiológica de queijos Minas frescal comercializados nas cidades de Arapongas e Londrina - PR. Revista do Instituto de Laticínios Cândido Tostes, Jul/Ago, no 369, 64: 48-54, 2009. Disponível em: <

https://www.revistadoilct.com.br/rilct/article/view/91/155 > . Acesso em: 23 de julho de 2019.

PINTO; et al. Qualidade Microbiológica de Queijo Minas Frescal Comercializado no Município de Santa Helena- PR, Brasil. Arquivos do Instituto Biológico. São Paulo: 2011 abr./jun; 78 (2),191-8. Disponível em: <

http://www.biologico.agricultura.sp.gov.br/uploads/docs/arq/v78_2/pinto.pdf >. Acesso em: 23 de julho de 2019.

RODRIGUES, D. D. S. Avaliação microbiológica de queijos Minas frescal comercializados na cidade de Viçosa-MG. 2013. $32 \mathrm{f}$. Monografia- Departamento de Nutrição e Saúde, Universidade Federal de Viçosa, Viçosa, 2013.

RICARDO, N. R.; et al. Análise físico-química de queijos minas frescal artesanais e industrializados comercializados em Londrina-PR. Revista Brasileira de Pesquisa em Alimentos, Campo Mourão (PR), v.2, n.2, p.89-95, Jul./Dez., 2011. Disponível em: <https://periodicos.utfpr.edu.br/rebrapa/article/viewFile/3349/2272>. Acesso em: 04 de maio de 2018. 
SALOTTI, B. M.; et al. Qualidade microbiológica do queijo Minas frescal comercializado no município de Jaboticabal, SP, Brasil. Arquivo do Instituto de Biologia, São Paulo, v.73, n.2, p.171-175, 2006. Disponível em: <

http://www.biologico.sp.gov.br/uploads/docs/arq/V73_2/salotti.PDF >. Acesso em: 04 e maio de 2018.

SANGALETTI, N. Estudo da vida útil do queijo Minas frescal disponível no mercado. 2007. 81f. Dissertação (Mestrado em Ciência e Tecnologia de Alimentos). Universidade de São Paulo Escola Superior de Agricultura "Luiz de Queiroz", Piracicaba, 2007. Disponível em: <http://www.teses.usp.br/teses/. Acesso em: 24 de julho de 2019.

SCOTT, R. Acidez y otrosanalisis químicos para elcontroldelproceso de elaboracion. Fabricación de queso. 2 ed. Zaragoza: ACRIBIA, p. 93-110, 1991.

Sebrae. Técnicas e boas práticas na produção de queijo. Disponível em: $<$ http://www.sebraemercados.com.br/wpcontent/uploads/2015/12/2014_02_27_RT_Agron_QueijoIN30_pdf.pdf >. Acesso em: 26 de abril de 2018.

SENGER, A. E. V.; BIZANI, D. Pesquisa de Staphylococcus aureus em queijo Minas frescal, produzido de forma artesanal e industrial, comercializado na cidade de Canoas/RS, Brasil. Revista de Ciências Ambientais, Canoas, v.5, n.2, p. 25 a 42, 2011. Disponível em: < https://revistas.unilasalle.edu.br/index.php/Rbca/article/view/259 >. Acesso em: 17 de julho de 2019.

SILVA, F. T. Queijo minas frescal. Embrapa Informação Tecnológica, Brasília DF, 50 p, 2005. Disponível em:

<https://ainfo.cnptia.embrapa.br/digital/bitstream/item/11884/2/00076200.pdf>. Acesso em: 26 de abril de 2018.

SILVA, C. A. M., LEITÃO, M. F. de F. Influência da temperatura de armazenamento na proliferação microbiana e no tempo de vida útil de queijo tipo "Minas frescal". In:

CONGRESSO BRASILEIRO DE CIÊNCIA E TECNOLOGIA DE ALIMENTOS, 4, 1980, Rio de Janeiro. Programa Oficial, Resumos... Rio de Janeiro: Sociedade Brasileira de Ciência e Tecnologia de Alimentos, 1980. p.186. Disponível em: < http://www.scielo.br/scielo.php?script=sci_nlinks\&ref=000074\&pid=S0103$8478200100060002400017 \& \operatorname{lng}=\mathrm{pt}>$. Acesso em 23 de junho de 2018.

SILVA, N. C.; TUNES, R. M. M.; CUNHA, M. F. Avaliação química de queijos Minas artesanais frescos e curados em Uberaba, MG. PUBVET, Londrina, V. 6, N. 16, Ed. 203, Art. 1358, 2012. Disponível em: <

http://www.pubvet.com.br/uploads/905b8f9ea0c5ec7f95bee67b5c530f87.pdf>. Acesso em: 04 de maio de 2018.

SILVA, T. V. Caracterização físico-química de queijos tipos Minas Frescal produzidos por pequenos produtores do município de Guarapuava e região. Salão de Extensão e Cultura, v. 
4, n. 6, p. 35, 2008. Disponível em: < https://anais.unicentro.br/sec/isec/pdf/resumo_64.pdf >. Acesso em: 17 de julho de 2019.

\section{Declaração de Interesse}

Os autores declaram não haver nenhum conflito de interesse

\section{Financiamento}

Este trabalho foi financiado pelos

próprios autores.

\section{Agradecimentos}

A Faculdade Dinâmica pela disponibilização do laboratório. A professora Letícia Monteiro Farias pela orientação, conselhos, incentivo, paciência e por todos os ensinamentos.

\section{Colaboração dos autores}

Motta coletou as amostras, realizou as análises e compilou os dados, Farias delineou o trabalho, e revisou o trabalho final. 